\title{
Finite Element Assessment of Moving Coil Actuator for HVDC breaker Applications
}

DOI:

10.1109/IECON.2016.7793857

Link to publication record in Manchester Research Explorer

\section{Citation for published version (APA):}

Vilchis-Rodriguez, D., Shuttleworth, R., \& Barnes, M. (2016). Finite Element Assessment of Moving Coil Actuator for HVDC breaker Applications. In 42nd Annual Conference of IEEE Industrial Electronics Society

https://doi.org/10.1109/IECON.2016.7793857

\section{Published in:}

42nd Annual Conference of IEEE Industrial Electronics Society

\section{Citing this paper}

Please note that where the full-text provided on Manchester Research Explorer is the Author Accepted Manuscript or Proof version this may differ from the final Published version. If citing, it is advised that you check and use the publisher's definitive version.

\section{General rights}

Copyright and moral rights for the publications made accessible in the Research Explorer are retained by the authors and/or other copyright owners and it is a condition of accessing publications that users recognise and abide by the legal requirements associated with these rights.

\section{Takedown policy}

If you believe that this document breaches copyright please refer to the University of Manchester's Takedown Procedures [http://man.ac.uk/04Y6Bo] or contact uml.scholarlycommunications@manchester.ac.uk providing relevant details, so we can investigate your claim.

\section{OPEN ACCESS}




\title{
Finite Element Assessment of Moving Coil Actuator for HVDC breaker Applications
}

\author{
D.S. Vilchis-Rodriguez, R. Shuttleworth and M. Barnes \\ School of Electrical and Electronic Engineering, University of Manchester, \\ Manchester, M13 9PL UK \\ Damian.Vilchis-Rodriguez@manchester.ac.uk
}

\begin{abstract}
This paper assesses the suitability of the moving coil actuator for use as an ultra-fast, long stroke linear drive for HVDC breaker applications. With the help of FEA, a sensitivity analysis of the actuator is conducted in order to better understand how the different design parameters affect the actuator performance. Based on this assessment a high performance actuator design has been implemented using FEA software. Simulation results show the suitability of the moving coil design as an ultra-fast linear driver. Efficiency of the proposed moving-coil design has been calculated and shows a remarkable advantage over other high speed actuator designs.
\end{abstract}

Keywords-HVDC, DC breaker, linear actuators, moving coil, Thomson coil

\section{INTRODUCTION}

In order to better integrate renewable power generation into traditional power systems the implementation of multi-terminal HVDC networks has been proposed [1-3]. Due to their high flexibility Voltage Source Converter (VSC) based multiterminal HVDC systems are seen as the most suitable alternative. However the high power electronics present in VSC HVDC stations possess poor overcurrent capability [4], therefore during a DC link fault, rapid isolation of the converter station is required. Very fast acting protection is essential to ensure safe operation of the VSC based DC grid [5, 6].

At present only solid-state based interruption has the capability to break a fault current in less than $1 \mathrm{~ms}[5,7]$. However the relatively high conduction losses of solid-state circuit breakers reduce their practicality $[6,8]$. On the other hand low loss mechanical breakers rely on a mechanically operated switch to provide voltage isolation and are therefore limited by the mechanical speed of the system. In order to improve the performance of mechanical HVDC breakers a combination of solid-state and mechanically operated switches (hybrid breaker) has been proposed to achieve DC current interruption $[5,6]$. However to make the hybrid concept compatible with DC systems, ultra-fast actuators are required to operate the mechanical switch.

For ultra-fast actuation the preferred actuator technology is based on the Thomson Coil (TC) $[6,9,10]$. In this actuator a flat coil with a low number of turns interacts with a conductive plate or armature. A current impulse injected in the coil results in a time varying magnetic field that produces eddy currents in the armature. Due to the direction of the armature induced

This work was funded as part of the UK EPSRC, FCL/CB: An Integrated VSC-HVDC Fault Current Limiter/Breaker project, EP/L021552/1. currents, a repulsive magnetic force occurs between armature and coil. As consequence of the operating principle the TC is a unidirectional device, and in order to achieve bidirectional displacement an additional coil on the other side of the armature is required. Using this operating principle opening speeds in excess of $20 \mathrm{~m} / \mathrm{s}$ have been reported [9-13]. The main drawback of this actuation mechanism is the low efficiency, typically in the $5-14 \%$ range, thus a high energy source needs to be readily available to ensure proper operation of the breaker, raising concerns about the practicality and maintainability of the device in isolated installations. The low efficiency of the TC is attributed to the decreasing magnetic link between coil and armature as the gap increases [11, 13]. In order to minimize the energy requirements of TC based interrupters, mass and stroke length minimization have been attempted [9, 10]. Thus a large number of lightweight, shortstroke, series connected switches, using actuators based on the TC principle have been proposed for medium voltage breakers $[9,10]$. However for very high voltages and fault currents typical of HVDC systems this practice is not suitable: moving mass and stroke length are governed by the carrying current and voltage levels, respectively. High voltage isolation requires a relatively long stroke. Meanwhile a large contact cross section area is required for high current conduction with low losses, thus interrupter moving mass increases as current increases. Consequently, an excessively high number of series and parallel mechanical switches would be necessary, giving rise to voltage sharing and synchronous operation problems [5]. The development of a more efficient actuator that allows higher mass displacement at relatively long strokes is required. In this regard repulsion driven designs with a higher efficiency than the TC, have been proposed [11, 13, 14]. However these devices also operate with variable air-gap length, thus limiting their efficiency over long strokes. A high efficiency solution operating with constant air-gap may be a more convenient alternative.

From existing electromagnetic based actuator technology, the moving iron, moving magnet and moving coil actuator concepts are capable of operation at constant air-gap. High controllability and bidirectional operation are other desirable attributes of these actuator technologies [15-18]. However, the extreme acceleration at which an actuator must operate in an ultra-fast application limits the usability of the moving iron and moving magnet concepts: their high moving mass has a negative effect on the actuators response time. In addition, the brittle nature of the permanent magnets (PMs) present in the 
moving magnet actuator gives rise to durability concerns. In contrast, the moving coil (MC) actuator possesses a relative low mass, allowing for a relatively fast response [18]. However, the suitability of the MC design for ultra-fast speed long stroke HVDC breaker applications has not been assessed. In this paper the performance of the moving coil actuator as an ultra-fast long stroke linear driver is assessed using FEA. Its performance is compared with results for a TC design for similar electric energy input. Its competitiveness in terms of acceleration, displacement and speed for a time window of 2 ms, characteristic of HVDC breaker applications [6], is assessed while its superior efficiency over the TC design is verified.

\section{MOVING COIL ACTUATOR}

\section{A. Operating principle}

A MC actuator is comprised of a coil mounted on a moving structure which acts as the plunger, sliding on a central core of ferromagnetic material. Permanent magnets fixed over external walls provide constant magnetic flux over a short air-gap. Additional ferromagnetic material is used to channel the magnetic flux radially through the coil. Fig. 1 shows an axial cut through a typical MC design.

The MC actuator uses the Lorentz force principle: a current carrying conductor located in a transverse magnetic field experiences a force $F$ of magnitude

$$
F=B I L
$$

Where $B$ is the magnetic field flux density, $I$ is the conductor current and $L$ is the length of the conductor. The direction of the resulting force acting over the coil is given by the right hand rule. Thus for a conductor carrying a current perpendicular to the PM magnetic field a vertical force will exist. It should be noted that the actuator moving component can be displaced in both directions, up or down, just by reversing the direction of the injected current. This is an important advantage compared to magnetic repulsion based actuators. Due to its construction the flux distribution of the MC design exhibits a bias toward downward displacement, therefore this direction will be assumed in all the subsequent analysis.
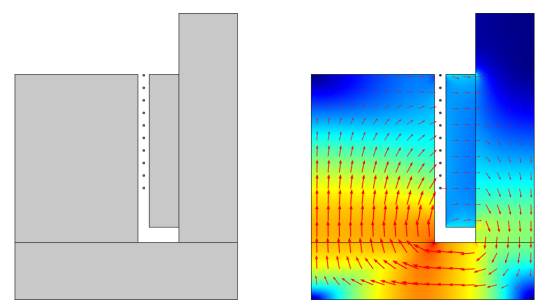

Fig. 1. MC actuator half symmetry cross section cut (left) and magnetic flux density distribution (right).

\section{B. MC FEA modelling}

According to (1), the force exerted over the coil in a $\mathrm{MC}$ design is a linear combination between the $B, I$ and $L$ variables. In practice $B$ is limited by the existing PM materials, while $L$ can be freely chosen. On the other hand $I$ depends on the excitation voltage, conductor material and coil length, thus $I$ is highly dependent on coil parameters as well as voltage excitation. Furthermore, $B$ will be affected by the magnetic properties of the material used in the construction of the magnetic circuit surrounding the coil, which in practical ferromagnetic materials has a nonlinear magnetic characteristic. Thus a tightly coupled set of nonlinear equations need to be solved in order to evaluate accurately the MC performance under transient operation. FE simulation has been shown to predict the behavior of ultra-fast actuators with high accuracy $[11,13]$. Therefore, in order to assess the MC actuator performance a FE model was implemented using COMSOL Multi-physics 5.2 software. For simplicity a 2D axially symmetric model was considered in the simulations. In addition inter-turn space due to wire insulation was neglected. The model implementation considers the solution of electrical circuits, magnetic fields, solid mechanics and moving mesh physics interfaces in a fully coupled solution algorithm. A set of ODEs, that represent the mechanical response of the system, is considered in the solution. The mechanical system equations are given by (2)-(4)

$$
\begin{aligned}
& F(t)=m a \\
& a(t)=d v / d t \\
& v(t)=d x / d t
\end{aligned}
$$

where $m$ is moving mass, $a$ is acceleration, $v$ is velocity and $x$ is the displacement of the moving element. During simulations the MC actuator is assumed to be excited by a capacitor, of capacitance $C$, charged at an initial voltage $V(0)$. Electrical to mechanical energy conversion efficiency is calculated as the kinetic energy output to electrical energy input ratio. The efficiency percentage can be calculated at any instant as

$n(t)=m v(t)^{2} /\left(C\left[V(0)^{2}-V(t)^{2}\right]\right) \times 100$

In this analysis the moving mass is comprised of the moving coil $\left(m_{c}\right)$ and mechanical load $\left(m_{l}\right)$ masses, thus the total moving mass can be expressed as

$m=m_{c}+m_{l}$

Consequently, the total force acting over the coil is given by the vectorial sum of the Lorentz force $\left(F_{l}\right)$ and the gravitational force exerted over the coil $\left(F_{c}\right)$ and load $\left(F_{m}\right)$ masses.

$F=F_{l}+F_{c}+F_{m}$

Low carbon steel 1117 is assumed as the ferromagnetic material while ideal PMs with 1.2 T remanence (comparable to that present in Neodymium PMs) are considered in the simulations.

\section{Sensitivity analysis}

In order to better understand how the different MC design parameters affect the actuator performance a sensitivity analysis was first conducted. The initial actuator parameter values are listed in Table I for completeness. In this analysis one design parameter was varied at a time in each simulation while keeping the rest of the parameters fixed at their initial values. Figs. 2-7 show simulation results for displacement for several design parameters over a time window of $2 \mathrm{~ms}$, typical in HVDC mechanical breaker operation [6]. 
TABLE I. MC INITIAL PARAMETERS

\begin{tabular}{|l|l|l|}
\hline \multicolumn{1}{|c|}{ Parameter } & \multicolumn{1}{c|}{ Value } & \multicolumn{1}{c|}{ Description } \\
\hline $\mathrm{V} 0$ & $80 \mathrm{~V}$ & Capacitor voltage \\
\hline $\mathrm{C} 1$ & $30 \mathrm{mF}$ & Capacitance \\
\hline $\mathrm{MCr}$ & $63 \mathrm{~mm}$ & Core radius \\
\hline $\mathrm{MCh}$ & $88 \mathrm{~mm}$ & Core height \\
\hline $\mathrm{Cmr}$ & $66 \mathrm{~mm}$ & Coil mean radius \\
\hline $\mathrm{Cnt}$ & 79 & Number of turns \\
\hline $\mathrm{Wt}$ & $30 \mathrm{~mm}$ & Wall thickness \\
\hline $\mathrm{CWw}$ & $0.912 \mathrm{~mm}$ & Conductor width (circular) \\
\hline $\mathrm{Ch}$ & $0.912 \mathrm{~mm}$ & Conductor height (circular) \\
\hline
\end{tabular}

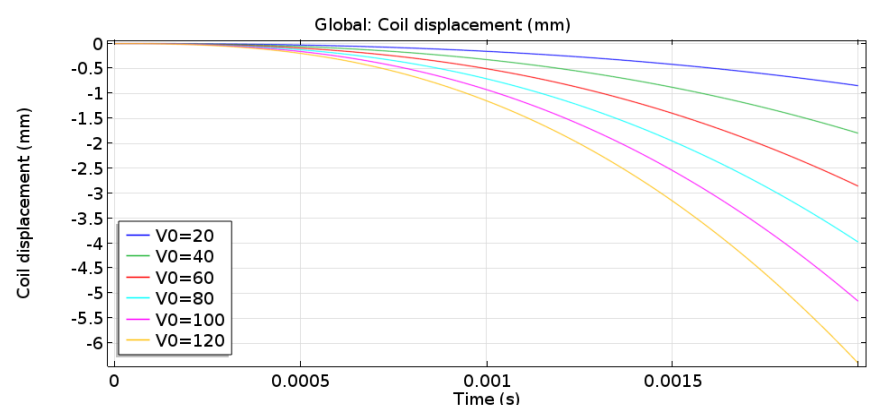

Fig. 2. $\mathrm{MC}$ actuator displacement for different capacitor initial voltages.

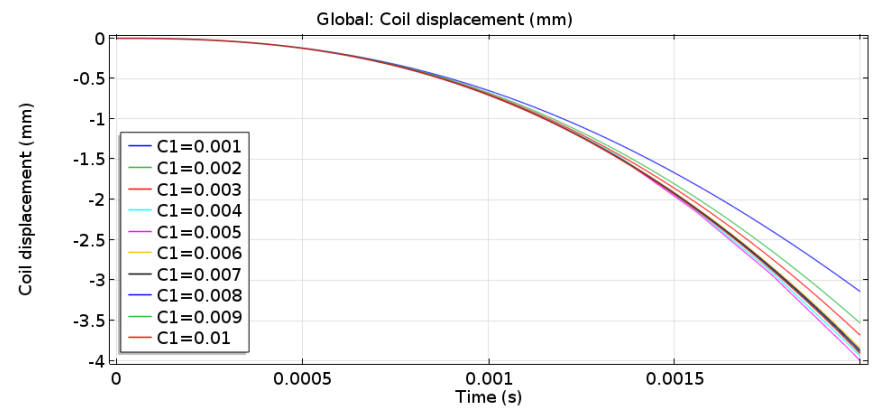

Fig. 3. MC actuator displacement for different capacitance values .

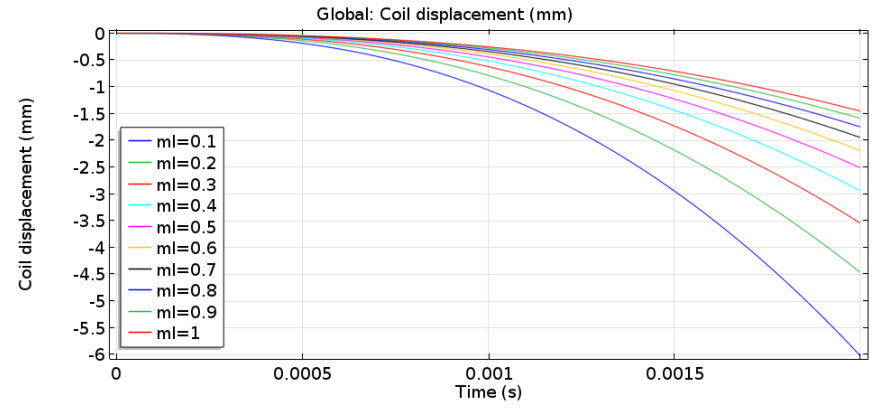

Fig. 4. MC actuator displacement for different mechanical loads.

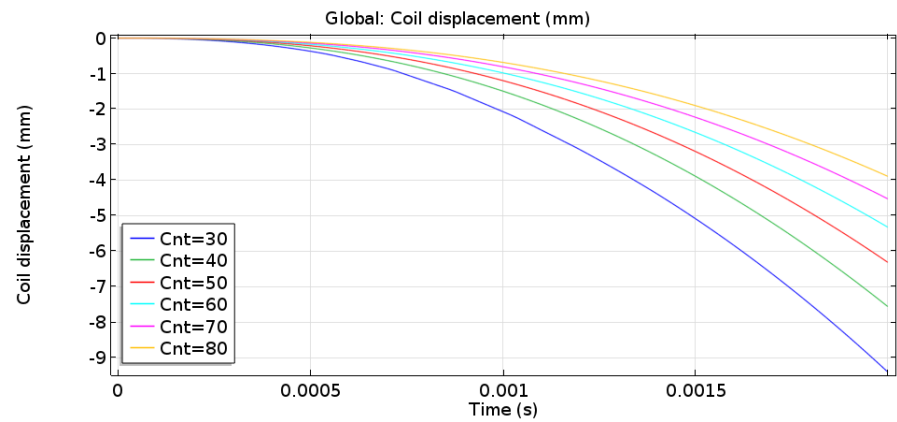

Fig. 5. MC actuator displacement for various turn numbers.

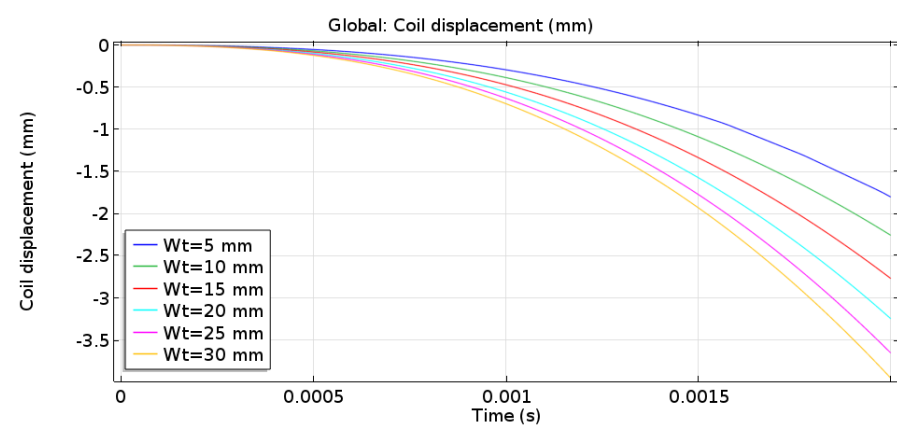

Fig. 6. MC actuator displacement for various wall thicknesses.

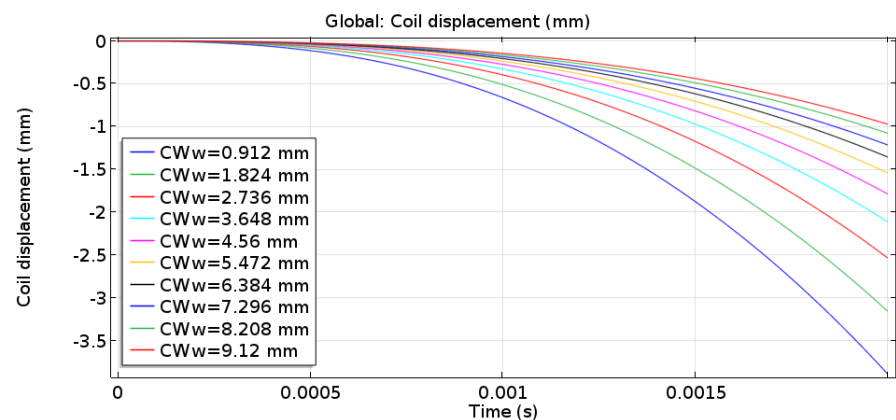

Fig. 7. MC actuator displacement for different conductor widths .

From the sensitivity analysis a few rules can be established:

- Increasing the number of coil turns results in an increase in efficiency; however there is an inverse relationship with displacement. Displacement is more critical than efficiency in ultra-high speed applications and should be favored in the actuator design.

- An increase in main core diameter or wall thickness is reflected as an increase in efficiency until a critical value is reached; only small increments in efficiency occur after this value.

- Increasing the input energy by increasing initial capacitor voltage or capacitance results in an increase in displacement. However, an optimal V-C combination exists, where efficiency is maximized for a fixed energy input.

- An increase in conductor cross section area may result in an increase in coil displacement depending on cross section geometry. An increase in conductor width was found to reduce actuator efficiency while an increase in height was beneficial to the actuator performance.

- Total mechanical load impacts negatively on actuator displacement. Moving mass must be minimized.

This set of rules can be used to refine the MC design.

\section{Performance ASSESSMENT}

Based on the set of rules listed in section II, refinement of the initial MC design was conducted following an iterative approach. It should be noted that due to its operating principle, the actuator coil should ideally remain between the PM face upper and lower boundaries during operation, thus generating 
maximum force. Consequently the stroke length of the $\mathrm{MC}$ is strongly linked with the physical dimension of the PM and walls. Thus the PM and wall dimensions of the MC actuator must be chosen in accordance with the stroke length requirements. This approach contrasts with that of repulsion driven based actuators, such as the TC, where no inherent ideal working region exists. Thus in order to define the stroke length of the $\mathrm{MC}$ a reference $\mathrm{TC}$ design is used. The maximum displacement obtained with the TC for an investigated $2 \mathrm{~ms}$ time window for a fixed electrical energy input and mechanical load was used to define the $\mathrm{MC}$ dimensions. A $1 \mathrm{~kg}$ mechanical load is also assumed in the simulations unless otherwise stated. Table II lists the design parameters of the reference TC design, and the parameters of the high performance $\mathrm{MC}$ design are listed in Table III.

From the values listed in Table III it is clear that a substantial increase in ferromagnetic material is required in order to improve the actuator performance when compared with the original design in Table I. This increase is necessary in order to allow a better distribution of the magnetic flux; otherwise magnetic saturation limits substantially the actuator performance. Another parameter that differs considerably from the original design is the conductor cross section, where in contrast with conventional designs a rectangular cross section with a relatively low width to height ratio was considered. It was found in this analysis that if the longer side of the conductor cross section is kept perpendicular to the PM flux, the actuator performance is substantially improved compared with a conventional circular conductor cross section geometry. In fact, the conductor cross section geometry was found to be essential to achieve the performance values reported in this research work. The relevance of the cross section area geometry for the actuator performance will be discussed in more detail below.

As reported in [13] the way in which the input electrical energy is shared between capacitor voltage and capacitance plays an important role in actuator efficiency. Thus a series of voltage and capacitance values for a fixed input energy of 2640J were used to identify the most convenient combination for the MC actuator. In this exercise, the voltage-capacitance combinations were deliberately chosen to be identical to those reported in [13] in order to allow a straight forward comparison with published results. Fig. 8 shows simulation results for the $\mathrm{MC}$ armature displacement and efficiency obtained using the different V-C combinations. Table IV summarizes results obtained from the FE simulations for the same $\mathrm{V}-\mathrm{C}$ combination $(727 \mathrm{~V}-10 \mathrm{mF})$ and load $(1 \mathrm{~kg})$ for the two ultrafast actuators designs assessed. From the simulation results it can be observed that the MC mechanical parameters are competitive with that achieved by the TC design. This demonstrates the viability of the MC actuator as an ultra-fast linear driver. It should be noted however that the efficiency achieved by the MC design is considerably higher than that of the TC. In addition a much lower peak current is required by the $\mathrm{MC}$ to achieve a comparable displacement for a similar $1 \mathrm{~kg}$ mechanical load. This is an important advantage of the MC, since lower rated ancillary components can be used in its operation, thus impacting favorably in the O\&M cost of the device.
TABLE II. TC ACTUATOR PARAMETERS

\begin{tabular}{|l|l|l|}
\hline \multicolumn{1}{|c|}{ Parameter } & \multicolumn{1}{c|}{ Value } & \multicolumn{1}{c|}{ Description } \\
\hline $\mathrm{Cnt}$ & 32 & Coil turns \\
\hline $\mathrm{At}$ & $3 \mathrm{~mm}$ & Armature thickness \\
\hline $\mathrm{Ar}$ & $44 \mathrm{~mm}$ & Armature radius \\
\hline $\mathrm{CWw}$ & $1.12 \mathrm{~mm}$ & Conductor width \\
\hline $\mathrm{Ch}$ & $4.48 \mathrm{~mm}$ & Conductor width \\
\hline
\end{tabular}

TABLE III. IMPROVED MC ACTUATOR PARAMETERS

\begin{tabular}{|l|l|l|}
\hline \multicolumn{1}{|c|}{ Parameter } & \multicolumn{1}{c|}{ Value } & \multicolumn{1}{c|}{ Description } \\
\hline $\mathrm{MCr}$ & $93 \mathrm{~mm}$ & Core radius \\
\hline $\mathrm{MCh}$ & $110 \mathrm{~mm}$ & Core height \\
\hline $\mathrm{Cmr}$ & $95.5 \mathrm{~mm}$ & Coil mean radius \\
\hline $\mathrm{Cnt}$ & 20 & Number of turns \\
\hline $\mathrm{Wt}$ & $40 \mathrm{~mm}$ & External wall thickness \\
\hline $\mathrm{CWw}$ & $2.0 \mathrm{~mm}$ & Conductor width \\
\hline $\mathrm{Ch}$ & $3.00 \mathrm{~mm}$ & Conductor height \\
\hline
\end{tabular}
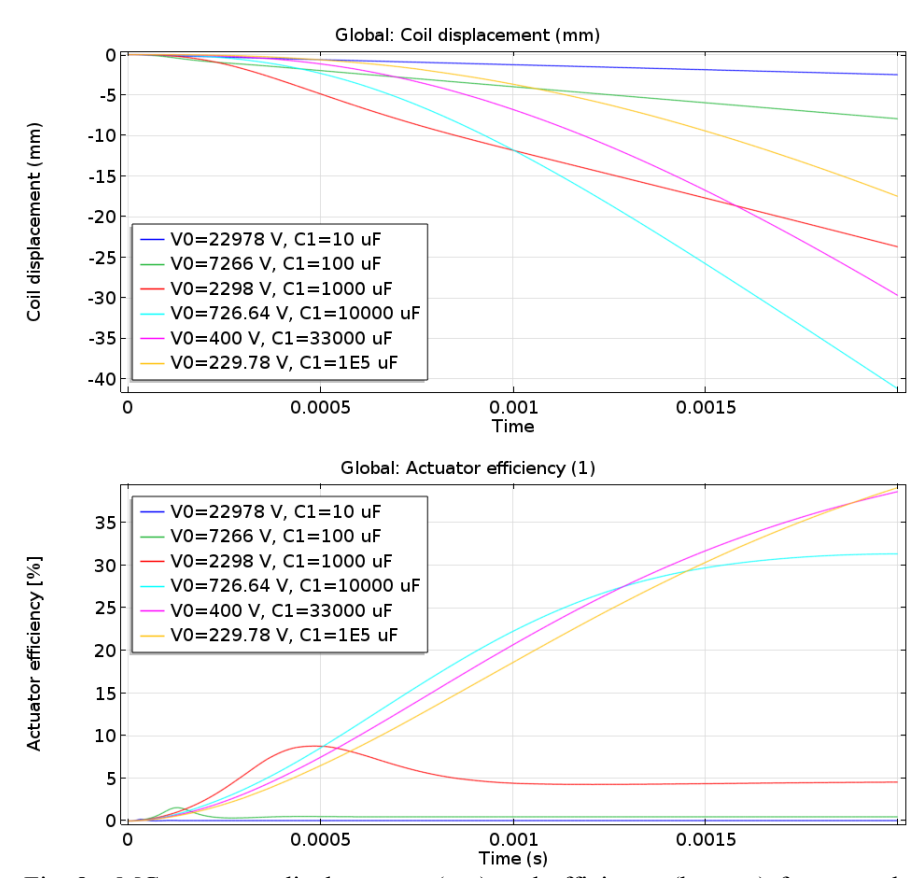

Fig. 8. MC armature displacement (top) and efficiency (bottom) for several V-C combinations.

TABLE IV. ULTRA-FAST ACTUATORS PARAMETERS

\begin{tabular}{|l|l|l|}
\hline \multicolumn{1}{|c|}{ Parameter } & \multicolumn{1}{c|}{ MC } & \multicolumn{1}{c|}{ TC } \\
\hline Displacement & $42 \mathrm{~mm}$ & $51 \mathrm{~mm}$ \\
\hline Efficiency & $32 \%$ & $22 \%$ \\
\hline Peak force & $52 \mathrm{kN}$ & $80 \mathrm{kN}$ \\
\hline Peak current & $5.7 \mathrm{kA}$ & $9 \mathrm{kA}$ \\
\hline
\end{tabular}

\section{MC PERFORMANCE IMPROVEMENTS}

The MC actuator performance can be further enhanced if the force acting over the coil can be increased without increasing significantly the coil mass. Air-gap field is mostly defined by the PM material and the potential to increase it is consequently very limited. Therefore, the potential of inductance and armature reaction reduction techniques to further improve the MC performance are assessed in this section. 


\section{A. MC actuator with conductive layer}

The use of a layer of highly conductive material around the central core to further improve the response of the MC actuator is investigated in this section. The conductive layer maintains the radial flux in a fixed position due to eddy currents induced within it. Fig. 9 shows a cross section of the proposed actuator geometry. During this analysis the central core radius is kept constant: any increase in the conductive layer depth is reflected in a decrease of the magnetic core material by the same amount. Thus all the actuator design parameters remain identical to those listed in Table III. In order to allow a comparison with the results in section III, the most favorable V-C combination (listed in Table IV) is used during the assessment. Figure 10 and Fig. 11 show the MC displacement and efficiency, respectively, obtained from a $2 \mathrm{~ms}$ simulation period when different depths of copper layer on the $\mathrm{MC}$ central core are considered. As can be seen from Fig. 10, for the considered V-C combination, a $3 \mathrm{~mm}$ conductive layer maximizes actuator displacement to $45 \mathrm{~mm}$. It is also observed in the results that the actuator efficiency suffers a considerable drop using this approach when compared with the conventional design in section III. It should be noted however that compared with the base design, higher peak current and force values of $8.1 \mathrm{kA}$ and $69 \mathrm{kN}$, respectively, occur. This increase in peak values is the result of a reduction of the coil impedance as perceived from its terminals. On the other hand, the drop in efficiency may be explained by the losses associated with the very high circulating current (136 kA peak current for the $3 \mathrm{~mm}$ thick layer) induced in the conductive layer due to the relatively high turn ratio, 20:1. As expected, this technique helps to improve the response time of the actuator, however given the tradeoff observed between displacement (average speed) and efficiency, careful design is required to maximize actuator performance.

\section{B. MC actuator with differential winding}

Another alternative to improve the performance of the MC actuator is to use a differential winding arrangement. In this configuration a second winding with current flowing in the reverse direction, and paired with PMs with inverted polarity, is mechanically and electrically series connected with the normal winding in a vertical stack, Fig. 12; the mmfs from each coil of the differential winding are in opposition. In this design Cnt refers to the number of turns per coil, therefore the total actuator turns is two times Cnt. In addition the PM face height is sized accordingly. Fig. 13 shows the simulation results for displacement and efficiency for the $\mathrm{MC}$ with differential windings and for different turn numbers.

As can be seen from the simulation results in Fig. 13, the actuator with the differential winding surpasses the performance indicators of the conventional design for an identical number of total turns. For 20 total turns the actuator with the differential winding reaches $50 \mathrm{~mm}$ displacement at the end of the investigated $2 \mathrm{~ms}$ event window. This contrasts with $42 \mathrm{~mm}$ for the conventional design. In addition the actuator efficiency peaks at $36 \%$, compared with $30 \%$ of the normal design. This increase in overall performance is however at the expense of an increase in PMs, magnetic material and further design complexity. In contrast, the flux distribution in Fig. 12 suggests that the base element can be removed without considerably affecting actuator performance. This observation was corroborated by numerical simulation results that showed identical performance without the base component. Removal of the base offsets some of the additional magnetic material required due to the taller core and external wall required by this arrangement. In any case a cost benefit analysis is required in order to assess the pertinence of this arrangement. Nevertheless from a performance point of view, the advantages of this design are evident. Moreover, if the two techniques assessed to improve MC performance are combined a further increase in displacement is possible. For example, with the 10 turns per coil differential actuator and a $3 \mathrm{~mm}$ copper layer, $53 \mathrm{~mm}$ displacement (not shown) was reached for the $2 \mathrm{~ms}$ event window. This displacement surpasses the displacement obtained with the TC actuator in section III. Even more, by further escalating the differential design, higher efficiencies without loss of mechanical performance are possible. For instance, for a double differential winding arrangement displacements varying between 51 and $55 \mathrm{~mm}$ were achieved for 5-8 turns per coil, with efficiencies in the range of $33-49 \%$ (Fig 14), further highlighting the benefits of the differential design.

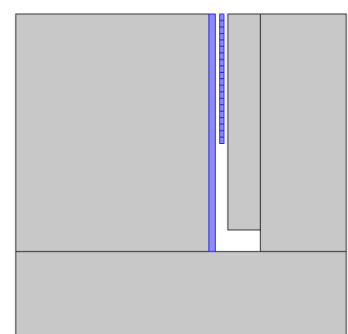

Fig. 9. MC actuator with a conductive layer around the central core

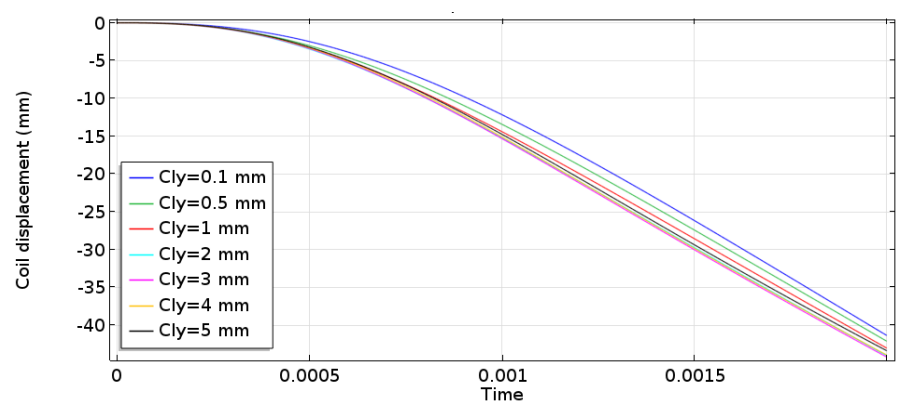

Fig. 10. Displacement for MC actuator with copper layer.

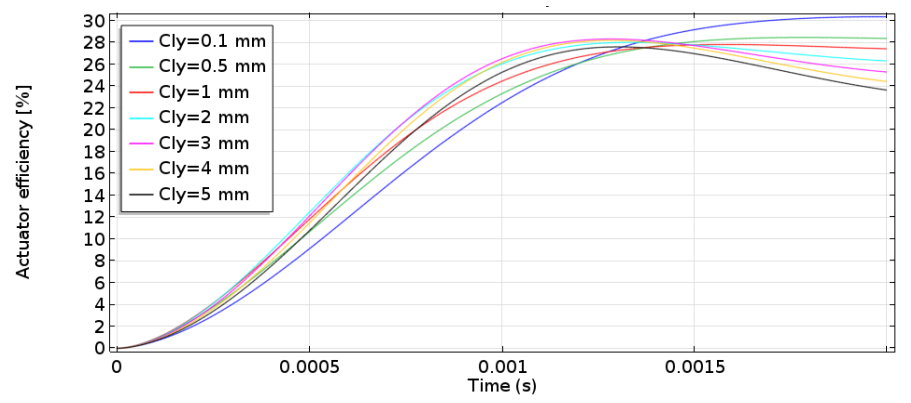

Fig. 11. Efficiency for MC actuator with copper layer. 

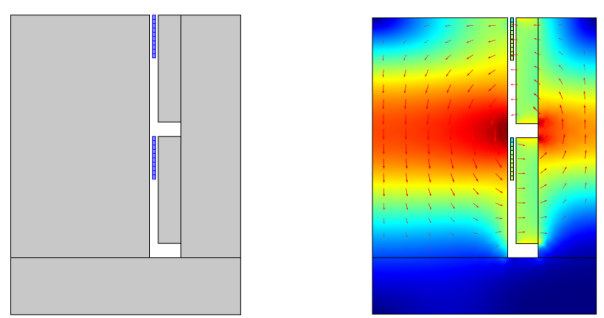

Fig. 12. MC with differential winding arrangement (left) and magnetic flux density distribution (right).
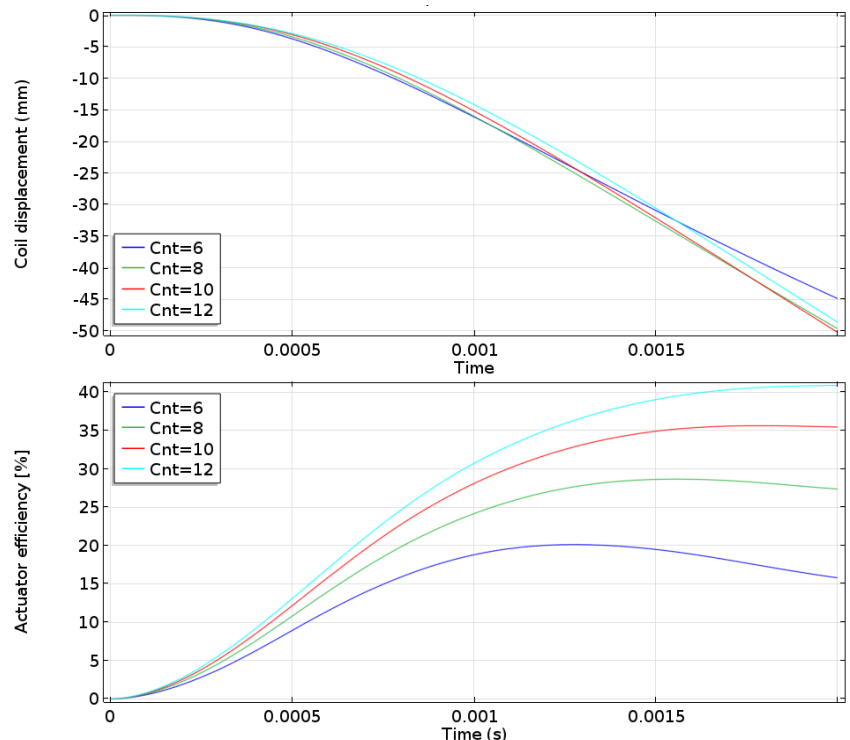

Fig. 13. MC actuator with differential winding, displacement (top) and efficiency (bottom).
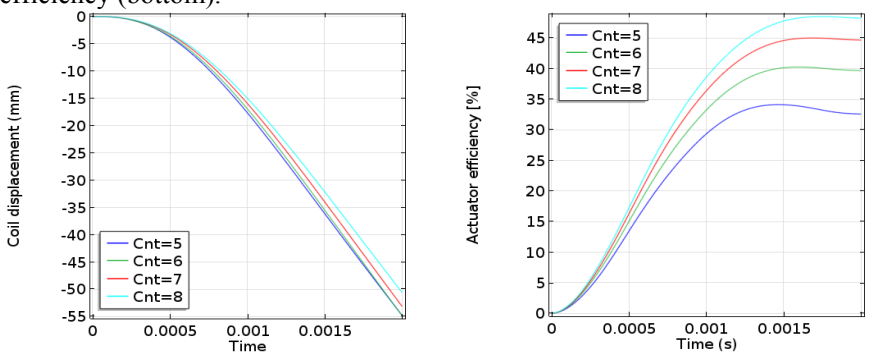

Fig. 14. Displacement (left) and efficiency (right) for MC actuator with double differential winding.

\section{CONCLUSIONS}

In this paper the suitability of the MC actuator as an ultrafast linear driver for HVDC breaker applications was assessed using FEA software. The MC design performance was compared with that of the TC actuator. Two techniques to improve the performance of the $\mathrm{MC}$ were also considered. Compared with the conventional MC design, the use of a conductive core layer produced slightly faster response and higher force while the use of a differential winding arrangement provided higher efficiency without loss of mechanical performance. The use of these techniques resulted in mechanical performance and efficiency that exceed those of the TC design, turning the MC actuator into a suitable candidate for use in HVDC breaker applications. However, the extra complexity of the MC design and costly materials required for its construction may impair its adoption. Nevertheless, given the
$\mathrm{MC}$ actuator potential to operate at a much higher efficiency than the TC design, the MC actuator may be a more convenient solution for use in installations where electric energy is scarce or difficult to provide, thus enabling simpler operation and maintenance of the actuator and associated infrastructure.

\section{REFERENCES}

[1] J.W. Feltes, B.D. Gemmell, D. Retzmann, "From Smart Grid to Super Grid: Solutions with HVDC and FACTS for grid access of renewable energy sources," Power and Energy Society General Meeting, 2011 IEEE , pp.1,6, 24-29 July 2011

[2] D. Van Hertem, M. Ghandhari, "Multi-terminal VSC HVDC for the European supergrid: Obstacles", Renewable and Sustainable Energy Reviews, Volume 14, Issue 9, December 2010, Pages 3156-3163.

[3] T.K. Vrana, R.E. Torres-Olguin, B. Liu, T.M. Haileselassie, "The North Sea Super Grid - a technical perspective," AC and DC Power Transmission, 2010. ACDC 9th IET International Conference on, pp.1,5, 19-21 Oct. 2010

[4] N. Flourentzou, V.G. Agelidis and G.D. Demetriades, "VSC-Based HVDC Power Transmission Systems: An Overview," in IEEE Transactions on Power Electronics, vol. 24, no. 3, pp. 592-602, March 2009.

[5] C.M. Franck, "HVDC Circuit Breakers: A Review Identifying Future Research Needs," Power Delivery, IEEE Transactions on, vol.26, no.2, pp.998,1007, April 2011

[6] J. Häfner, B. Jacobson, "Proactive Hybrid HVDC Breakers - A key innovation for reliable HVDC grids," (Cigré Bologna, Paper 0264, 2011)

[7] C. Meyer and R. De Doncker, "Solid-state circuit breaker based on active thyristor topologies," IEEE Trans. Power Electron., vol. 21, pp. 450-458, Mar. 2006.

[8] H. Pang, G. Tang, and Z. He, "Evaluation of losses in VSC-HVDC transmission system," in IEEE Power and Energy Society General Meeting Conversion and Delivery of Electrical Energy in the 21st Century, Pittsburgh, PA, USA, Jul. 2008, pp. 1 -6.

[9] W. Holaus, K. Frohlich, "Ultra-fast switches- a new element for medium voltage fault current limiting switchgear," Power Engineering Society Winter Meeting, 2002. IEEE, pp.299,304 vol.1, 2002

[10] M. Steurer, K. Frohlich, W. Holaus, K. Kaltenegger, "A novel hybrid current-limiting circuit breaker for medium voltage: Principle and test results," IEEE Trans. Power Del., vol. 18, no. 2, pp. 460-467, Apr. 2003.

[11] A. Bissal, J. Magnusson, G. Engdahl, "Comparison of Two Ultra-Fast Actuator Concepts," Magnetics, IEEE Transactions on, vol.48, no.11, pp.3315,3318, Nov. 2012

[12] V. Puumala and L. Kettunen, "Electromagnetic Design of Ultrafast Electromechanical Switches," Power Delivery, IEEE Transactions on, vol. 30, no. 3, pp. 1104-1109, June 2015.

[13] A. Bissal, J. Magnusson, G. Engdahl, "Electric to Mechanical Energy Conversion of Linear Ultrafast Electromechanical Actuators Based on Stroke Requirements," Industry Applications, IEEE Transactions on, vol.51, no.4, pp.3059,3067, July-Aug. 2015.

[14] D.S. Vilchis-Rodriguez, R. Shuttleworth, M. Barnes, "Double-sided Thomson coil based actuator: Finite element design and performance analysis", 8th IET International Conference on Power Electronics, Machines and Drives (PEMD 2016), Glasgow, UK, 19-21 April 2016.

[15] T. Teo, H. Zhu, S.L. Chen, G. Yang, C. Pang, "Principle and Modeling of A Novel Moving Coil Linear-Rotary Electromagnetic Actuator," in IEEE Transactions on Industrial Electronics, to be published.

[16] A. Okyay, M.B. Khamesee and K. Erkorkmaz, "Design and Optimization of a Voice Coil Actuator for Precision Motion Applications," in IEEE Transactions on Magnetics, vol. 51, no. 6, pp. 1-10, June 2015.

[17] D.B. Roemer, M.M. Bech, P. Johansen and H.C. Pedersen, "Optimum Design of a Moving Coil Actuator for Fast-Switching Valves in Digital Hydraulic Pumps and Motors," in IEEE/ASME Transactions on Mechatronics, vol. 20, no. 6, pp. 2761-2770, Dec. 2015.

[18] Y. Liu, M. Zhang, Y. Zhu, J. Yang and B. Chen, "Optimization of Voice Coil Motor to Enhance Dynamic Response Based on an Improved Magnetic Equivalent Circuit Model," in IEEE Transactions on Magnetics, vol. 47, no. 9, pp. 2247-2251, Sept. 2011. 